\title{
CONSIDERAÇÕES SOBRE O MÉTODO DE DATAÇÃO PELO CARBONO-14 E ALGUNS COMENTÁRIOS SOBRE A DATAÇÃO DE SAMBAQUIS
}

\section{Introdução}

Nos estudos do Quaternário recente, o método de datação rádio-isotópico do ${ }^{14} \mathrm{C}$ é de longe o mais utilizado. Dada a distribuição ubiquista deste elemento, esta técnica é válida em qualquer lugar do mundo e serve para datar madeira, ossos, conchas, sedimentos etc. Ela é ideal para datar os eventos ligados à história do homem desde o paleolítico até a época histórica, tendo-se revelado um instrumento primordial para a arqueologia.

Vários problemas podem se apresentar em relação à cronologia de sedimentos quaternários e de sítios arqueológicos, de modo que consideramos útil apresentar alguns comentários a esse respeito. Principalmente, deve-se levar em conta as diversas fontes de erros possíveis nas datações e as múltiplas formas de apresentação das datas.

\section{Princípios do método de datação pelo radiocarbono}

O carbono-14 é um isótopo radioativo do carbono produzido continuamente na alta atmosfera pela irradiação cósmica do ${ }^{14} \mathrm{~N}$. Com o tempo, os átomos de ${ }^{14} \mathrm{C}$ se desintegram por perda espontânea de radioatividade e se transformam num novo elemento $\left({ }^{14} \mathrm{~N}\right.$, ${ }^{40} \mathrm{~K},{ }^{40} \mathrm{Ar} \mathrm{ou}{ }^{40} \mathrm{Ca}$ ). Ao longo do tempo geológico, um equilíbrio dinâmico foi estabelecido entre a velocidade de produção do ${ }^{14} \mathrm{C}$ e sua velocidade de desintegração no estoque global. Este equilíbrio foi rompido com a primeira explosão atômica na atmosfera, devido ao aumento artificial da produção deste elemento.

Uma vez formados, os átomos de ${ }^{14} \mathrm{C}$ são incorporados ao $\mathrm{CO}_{2}$ atmosférico e assimilados no ciclo do carbono dos organismos vivos, da mesma forma que os átomos dos dois isótopos estáveis, ${ }^{12} \mathrm{C} \mathrm{e}{ }^{13} \mathrm{C}$. O conteúdo em ${ }^{14} \mathrm{C}$ nos tecidos orgânicos está em equilíbrio com o conteúdo atmosférico, devido às trocas que se efetuam durante toda a vida do organismo. Quando ele morre, essas trocas deixam de existir e $0{ }^{14} \mathrm{C}$ começa a se desintegrar continuamente, sem ser renovado.
A vida média do ${ }^{14} \mathrm{C}$ é de 5730 anos. Isto significa que um organismo que morreu há 5730 anos tem atualmente a metade do seu conteúdo original em ${ }^{14} \mathrm{C}$. Ele terá $25 \%$ deste conteúdo daqui a 5730 anos, e assim por diante. Assim sendo, a idade radiocarbono de uma amostra fóssil pode ser obtida comparandose a radioatividade específica ${ }^{14} \mathrm{C} /{ }^{12} \mathrm{C}$ desta amostra com a radioatividade especifica de um padrão de referência. O padrão utilizado é de 1950 e o resultado é apresentado em "anos antes do presente" (BP, before present), isto é, "antes do ano 1950"

Quando os princípios da datação pelo radiocarbono foram definidos, a vida-média do ${ }^{14} \mathrm{C}$ foi estimada em 5568 anos. Cálculos mais precisos indicaram que ela é na verdade de $5730 \pm 30$ anos, mas para evitar confusões os laboratórios continuaram usando a "vida-média de Libby", i.e., 5568 anos (Bradley 1985). A diferença entre a idade estimada a partir da "vida-média de Libby" e a idade "verdadeira" é constante e de pequena magnitude. A correção pode ser obtida multiplicando-se o resultado fornecido pelo laboratório por 1,03 (Goudie 1981, apud Salgado-Labouriau 1994).

No entanto, diversos outros fatores provocam distorções muito mais importantes entre as datas radiocarbono e as datas reais. As principais destas fontes de erro são apresentadas a seguir, assim como as correções que podem ser feitas.

\section{Incorporação \\ diferencial do ${ }^{14} \mathrm{C}$ pelas plantas}

Um dos princípios do método de datação pelo radiocarbono é que os vegetais assimilam os diferentes isótopos do carbono nas mesmas proporções em que eles existem na atmosfera. Este não é sempre o caso. $\mathrm{O}^{12} \mathrm{C}$ tem tendência a ser fixado preferencialmente ao ${ }^{14} \mathrm{C}$, e isto de acordo com taxas que variam segundo o ciclo fotossintético de cada espécie. A magnitude desta distorção pode ser conhecida pela medida do teor de ${ }^{13} \mathrm{C} \mathrm{da}$ amostra, pois a fixação do ${ }^{14} \mathrm{C}$ e do ${ }^{13} \mathrm{C}$ é proporcional. 
Assim, de modo a normalizar os resultados e tornálos comparáveis entre si, um acordo internacional determina a correção de todas as datas segundo um valor de $\mathrm{d}^{13} \mathrm{C}$ de $-25 \%$, que é o valor médio na madeira (Bradley 1985).

Atualmente, todos os laboratórios de datação fornecem os resultados sob forma de "datas radiocarbono convencionais", isto é, normalizadas pelo $\mathrm{d}^{13} \mathrm{C}$ utilizando os valores médios estimados para diversos componentes orgânicos (Stuiver \& Polach 1977, apud Stuiver \& Reimer 1993). O d ${ }^{13} \mathrm{C}$ da amostra corresponde à diferença relativa entre esta amostra e um padrão de referência. $O$ padrão de referência internacional mais freqüentemente utilizado é o Pee Dee Belemnite (PDB), que corresponde ao $\mathrm{CO}_{2}$ extraído a $25^{\circ} \mathrm{C}$ do rostro de um belemnite da formação "Pee Dee", do Cretáceo de Carolina do Sul, EUA (McCrea 1950, Craig 1957, apud Tasayco-Ortega 1996).

Não se deve esquecer que esta correção não foi feita para as datações mais antigas (até mais ou menos a metade da década de 70), e que é indispensável levar este fato em consideração para interpretá-las.

\section{Variações do teor de ${ }^{14} \mathrm{C}$ na atmosfera}

Um outro princípio deste método de datação é a premissa de que o teor $\mathrm{de}^{14} \mathrm{C}$ na atmosfera tenha se mantido constante ao longo do tempo. No entanto, flutuações importantes foram detectadas. Elas são provavelmente devidas a fatores como a variação da taxa de produção do radiocarbono na atmosfera, a variação na taxa de troca do radiocarbono entre os diversos reservatórios geoquímicos e a variação da quantidade total de $\mathrm{CO}_{2}$ na atmosfera, biosfera e hidrosfera (Bradley 1985).

As variações do teor de ${ }^{14} \mathrm{C}$ na atmosfera podem ser conhecidas de forma bastante precisa através de estudos dendrocronológicos. Quando se encontram seqüências bem datadas de anéis de crescimento de árvores, elas são um instrumento ideal para a calibração do radiocarbono.

$\mathrm{O}$ estudo de milhares de anéis de crescimento permitiu a calibração das datas ${ }^{14} \mathrm{C}$ para os últimos 11.000 anos com uma precisão de 10 a 20 anos (Becker 1993). Para épocas mais antigas, até os últimos 30.000 anos, a calibração foi possível graças a datações urânio-tório (U-Th) sobre corais (Bard et al. 1990). Um banco de dados baseado nestes estudos permite atualmente o cálculo das datas ca- libradas até 18.000 anos convencionais BP, com a ajuda de programas de calibração como o CALIB 3.0 (Stuiver \& Reimer 1993).

Devido a uma homogeneização incompleta, existe uma diferença no conteúdo atmosférico de ${ }^{14} \mathrm{C}$ entre os dois hemisférios. Para a calibração de amostras provenientes do Hemisfério Sul, deve-se previamente subtrair 40 anos da data fornecida pelo laboratório. No caso de amostras posteriores ao ano de 1850 , a diferença é menor e pode ser negligenciada (Stuiver \& Reimer 1993).

\section{O efeito reservatório}

Efeito reservatório é o efeito de envelhecimento aparente das datas radiocarbono, freqüente na datação de organismos marinhos. Ele é consequiência do fato de que a taxa de renovação das águas oceânicas é muito mais lenta do que a da atmosfera, sobretudo para a água situada abaixo da termoclina (camada de água do mar com forte gradiente vertical de temperatura, entre a água quente da superfície e a água fria do fundo).

As águas profundas podem ficar centenas de anos sem ter contato com a atmosfera. Durante este tempo, seu teor em ${ }^{14} \mathrm{C}$ diminui. Num organismo marinho atual, o teor de ${ }^{14} \mathrm{C}$ está em equilíbrio com o da água onde ele vive. Ele em geral apresenta datações entre 320 e 450 anos quando habita águas oceânicas superficiais, mas que podem ir até 2500 anos quando habita águas profundas (Bradley 1985).

$\mathrm{O}$ efeito reservatório é acentuado em zonas de ressurgência. Nestes locais, águas profundas pobres em ${ }^{14} \mathrm{C}$ se misturam às águas superficiais, que estão em equilíbrio com o $\mathrm{CO}_{2}$ atmosférico. A datação de organismos destas regiões fornece idades intermediárias entre as águas profundas e superficiais, isto é, idades envelhecidas com relação às obtidas a partir de organismos similares que habitam à mesma profundidade em zonas sem ressurgência (Bradley 1985).

Estas datações aparentes podem ser corrigidas quando se conhece a diferença da atividade específica entre $0{ }^{14} \mathrm{C}$ do reservatório (neste caso, o oceano) e o da atmosfera. Elas não são obrigatoriamente constantes no tempo e podem ser obtidas, por exemplo, a partir de datações U-Th de corais.

Calibrações médias para os oceanos são atualmente disponíveis até 12.000 anos BP (Stuiver \& Braziunas 1993). Por medida de simplificação, 
um valor constante de 400 anos é em geral utilizado na estimativa do efeito reservatório. Este valor é a média do que é observado em alto mar nas latitudes baixas e médias (Stuiver \& Braziunas 1993; Bard et al. 1993).

Um envelhecimento aparente das datas radiocarbono também é freqüente em regiões onde existem muitas formações carbonatadas, ou quando um lago é alimentado por descargas de água subterrânea contendo uma certa proporção de carbonatos fósseis dissolvidos. Quando estes efeitos são detectados, os autores em geral propõem coeficientes de correção calculados a partir de medidas sobre o ambiente atual, ou por comparação com datas obtidas por outros métodos, por exemplo o UTh (Sylvestre 1997).

\section{O efeito de rejuvenescimento}

Um rejuvenescimento aparente das datações também é freqüente. Ele é em geral devido à contaminação por material atual (radicelas, matéria orgânica dissolvida etc.), quando estes elementos não são completamente eliminados pelo tratamento químico ao qual a amostra é submetida.

Outra fonte de rejuvenescimento das datações medidas é a recristalização do carbonato, incorporando carbono recente após o depósito. Este processo é difícil de detectar quando a recristalização é fraca, mas características mineralógicas e isotópicas podem permitir a identificação das amostras onde uma possibilidade de recristalização deve ser considerada (Sylvestre 1997). rida à de "anos AP" freqüentemente utilizada no Brasil.

As datas calibradas devem ser apresentadas sob a forma "anos cal BP" Elas podem também ser transformadas em "datas calendário" ou "anos reais" e neste caso devem ser apresentadas sob a terminologia "BC" (antes de Cristo) ou "AD" ("anno Domini", i.e., depois de Cristo).

A transformação das datas calendário em datas calibradas pode ser feita simplesmente somando 1950 anos à data calendário $\mathrm{BC}$ ou subtraindo a data calendário $\mathrm{AD}$ de 1950, e vice-versa (ver exemplo na Tabela I).

É extremamente importante conhecer as limitações dos métodos de datação e levar em consideração as margens de erro. As datas radiocarbono são, como todas as medidas de radioatividade, enunciados de probabilidade. Cada data é definida como o ponto médio de uma curva de Poisson com o seu desvio padrão, e representa unicamente um nível conhecido de probabilidade (Bradley 1985).

A margem estatística fornecida pelos laboratórios de datação, que deve ser indicada em todos os casos, é o desvio padrão (1 sigma). $O$ desvio padrão determina o intervalo no qual a data radiocarbono exata tem duas chances sobre três de se encontrar, i.e., o "intervalo de confiança". Por exemplo, uma datação de $5000 \pm 100$ anos BP significa que há $68 \%$ de probabilidade de que a verdadeira data esteja entre 4900 e 5100 ans BP ( 1 sigma), 95\% de probabilidade de que ela esteja entre 4800 e 5200 anos BP ( 2 sigma) e $99 \%$ de que ela esteja entre 4700 e 5300 anos BP (3 sigma).

Note que as datas calibradas são em geral apresentadas com 2 sigma de intervalo de confiança.

\section{Apresentação das datas radiocarbono}

As datas radiocarbono devem ser apresentadas de modo a não provocar confusão. A terminologia "anos BP", ou "anos ${ }^{14} \mathrm{C}$ BP" deve ser reservada à data convencional, isto é, à data fornecida pelo laboratório de datação, em geral normalizada pelo $\mathrm{d}^{13} \mathrm{C}$. Esta terminologia, adotada internacionalmente, deve ser prefe-
Tabela I

\begin{tabular}{|c|c|c|c|}
\hline material datado & data convencional & data calibrada (2 s) & data calendário ( $2 \mathrm{~s}$ ) \\
\hline carvão & $1000 \pm 50 \mathrm{BP}$ & $980-790 \mathrm{cal} \mathrm{BP}$ & $970-1160 \mathrm{AD}$ \\
\hline conchas & $1000 \pm 50 \mathrm{BP}$ & $650-500 \mathrm{cal} \mathrm{BP}$ & $1300-1450 \mathrm{AD}$ \\
\hline carvão & $5000 \pm 100 \mathrm{BP}$ & $5920-5480 \mathrm{cal} \mathrm{BP}$ & $3970-3530 \mathrm{BC}$ \\
\hline conchas & $5000 \pm 100 \mathrm{BP}$ & $5570-5030 \mathrm{cal}$ BP & $3620-3080 \mathrm{BC}$ \\
\hline carvão & $12000 \pm 80 \mathrm{BP}$ & $14260-13670 \mathrm{cal} \mathrm{BP}$ & $12310-11720 \mathrm{BC}$ \\
\hline conchas & $12000 \pm 80 \mathrm{BP}$ & $13800-13310 \mathrm{cal}$ BP & $11850-11360 \mathrm{BC}$ \\
\hline
\end{tabular}

TABELA I - Calibração de datações radiocarbono obtidas sobre carvão e sobre conchas e transformação das datas calibradas em datas calendário. A calibração das datas obtidas sobre conchas foi feita considerando-se uma correção de efeito reservatório "global" para águas oceânicas superficiais. As datas apresentadas são hipotéticas; as calibrações foram feitas utilizando-se o programa CALIB 3.0 (Stuiver \& Reimer 1993). 


\section{Principais fontes de erro nas datações de sambaquis}

Uma das principais fontes de erro nas datações de sambaquis é provavelmente a ocorrência de inversões estratigráficas. De fato, Gaspar (1995/96) observa que problemas de estratigrafia são freqüentes nestes sítios. Eles podem ser devidos à manipulação do sedimento pelas populações que habitaram o sítio, à abertura de sepulturas e/ou ao nivelamento do solo habitado. Em geral estas inversões podem ser identificadas por critérios arqueológicos. Freqüentemente, no entanto, é a inversão de datas que atrai a atenção do arqueólogo para possíveis problemas estratigráficos.

Um efeito de rejuvenescimento devido à contaminação da amostra por matéria orgânica atual também é comum. Ele é mais frequiente quando a amostra provém de níveis superficiais e/ou quando a quantidade de material fornecida para a datação é muito pequena. Nestes casos, é possível que os elementos contaminantes não possam ser completamente eliminados pelo tratamento químico feito no laboratório de datação.

Naturalmente, um cuidado especial deve ser tomado durante a coleta da amostra para datação, a fim de evitar contato com substâncias orgânicas. No entanto, a utilização de células de flotação para lavar o sedimento e concentrar os carvões a serem datados não apresenta nenhum risco de contaminação (Fontugne, comunicação pessoal), desde que os carvões sejam em seguida bem secos em recipientes plásticos. Evita-se assim uma contaminação por fibras de papel ou pelo desenvolvimento de fungos quando o material é guardado úmido.

$\mathrm{O}$ efeito de rejuvenescimento também pode ocorrer quando os sambaquis apresentam concreções carbonatadas. Os carbonatos são particularmente susceptíveis à contaminação pelo carbono moderno, pois eles participam diretamente das reações químicas com as águas da chuva e do solo. A maior parte dos moluscos são primitivamente formados de aragonita, que pode se dissolver e recristalizar sob forma de calcita. Durante este processo pode haver incorporação de carbono moderno.

Por precaução, é importante evitar a datação de material proveniente de concreções.

Datações envelhecidas devido ao efeito reservatório são também comuns no caso de sambaquis. Elas se devem à prática de datar conchas marinhas. Como não existem ainda estimativas precisas para o efeito reservatório no litoral brasilei- ro, as correções são feitas levando-se em conta o efeito reservatório "global”, estimado em 400 anos. Estas correções são imprecisas, principalmente em zonas de ressurgência, como por exemplo na região de Cabo Frio, ou em áreas onde os moluscos vivem sobre rochas calcárias. Neste caso, os moluscos utilizam os carbonatos das rochas sobre as quais eles vivem, velhas de milhões de anos, na construção de suas conchas.

Em consequiência deve-se sempre que possível evitar a datação de conchas. Uma metodologia de amostragem adaptada, por exemplo a utilização de células de flotação (Ybert et al. 1997), permite quase sempre a recuperação de uma quantidade de carvão suficiente para a datação, sobretudo atualmente, quando as técnicas de AMS se tornam mais acessíveis.

\section{Conclusão}

Embora extremamente difundido, o método de datação pelo ${ }^{14} \mathrm{C}$ apresenta uma série de limitações que devem ser levadas em conta na interpretação dos resultados cronológicos. Diversos fatores de distorção das datas obtidas em laboratório são conhecidos, mas a maior parte deles pode ser corrigida. É indispensável se assegurar, antes de utilizar uma datação para interpretar seqüências cronológicas, se alguma correção, e qual, foi ou deve ser aplicada a este resultado (por exemplo, correção pelo $\mathrm{d}^{13} \mathrm{C}$ ou efeito reservatório).

No caso dos sambaquis, observa-se freqüentemente que as datações são feitas indistintamente sobre carvões e conchas, e que os resultados são comparados entre eles sem nenhuma correção. Ora, a calibração das datações com correção do efeito reservatório resulta num rejuvenescimento relativo das datas obtidas sobre conchas (Tabela I). Em consequiência, estes resultados não são diretamente comparáveis entre si, sob pena de induzir sérios erros de interpretação.

Tanto em sítios arqueológicos quanto em outros estudos do Quaternário recente, é importante privilegiar a datação de matéria orgânica terrestre (madeira, carvão, ossos, sedimentos orgânicos de origem terrestre...). Quando a datação sobre conchas ou sobre outros materiais susceptíveis de sofrer um efeito reservatório não pode ser evitada, ou quando estas datações devem ser comparadas com outras, é imprescindível levar este efeito em consideração e fazer as calibrações necessárias. 
Deve-se também dar uma atenção especial à apresentação dos resultados, e não comparar dados não comparáveis (por exemplo datas convencionais com datas calibradas, datas calibradas com anos reais etc.).

Estas recomendações podem ser úteis não somente aos estudiosos de sambaquis, mas a todos os pesquisadores que lidam com seqüências cronológicas obtidas a partir do radiocarbono. Ter consciência das limitações do método, efetuar sem- pre as correções pertinentes e atentar para o significado das datas obtidas pode nos conduzir a aproveitar todas as potencialidades deste método de datação. Sem dúvida, nossas interpretações de seqüências cronológicas serão muito aperfeiçoadas, e é possível que diversos problemas estratigráficos aparentes se revelem na verdade inexistentes!

Rita Scheel-Ybert*

\section{Referências Bibliográficas}

BARD, E.; ARNOLD, M.; FAIRBANKS, R.G.; HAMELIN, B. $1993{ }^{230} \mathrm{Th}-{ }^{234} \mathrm{U}$ and ${ }^{14} \mathrm{C}$ ages obtained by mass spectrometry on corals. Radiocarbon 35 (1): 191-199.

BECKER, B.

1993 An 11,000-year German oak and pine dendrochronology for radiocarbon calibration. $R a$ diocarbon 35 (1): 201-213.

BRADLEY, R.S

1985 Quaternary paleoclimatology. Methods of paleoclimatic reconstruction. Boston, Unwin Hyman. 472 p.

GASPAR, M.D.

1995/ Datações, construção de sambaqui e identidade

1996 social dos pescadores, coletores e caçadores. $\mathrm{Co}$ leção Arqueologia, Porto Alegre, 1 (1) : 377-398.

SALGADO-LABOURIAU, M.L.

1994 História ecológica da Terra. São Paulo, Edgar Blücher ltda. $307 \mathrm{p}$.

STUIVER, M.; BRAZIUNAS, T.F.

1993 Modeling atmospheric ${ }^{14} \mathrm{C}$ influences and ${ }^{14} \mathrm{C}$ ages of marine samples to 10,000 BC. Radiocarbon 35 (1): 137-189.
STUIVER, M.; REIMER, P.J.

1993 Extended ${ }^{14} \mathrm{C}$ data base and revised CALIB 3.0 ${ }^{14} \mathrm{C}$ age calibration program. Radiocarbon 35 (1): 215-230.

SYLVESTRE, F.

1997 La dernière transition glaciaire-interglaciaire (18 $000-8000{ }^{14} \mathrm{C}$ ans B.P.) des Andes Tropicales du Sud (Bolivie) d'après l'étude des diatomées. Tese de Doutorado. MNHN. Paris. 311 p.

TASAYCO-ORTEGA, L.A.

1996 Variations paléohydrologiques et paléoclimatiques d'une région d'upwelling au cours de l'Holocène: enregistrement dans les lagunes côtières de Cabo Frio (État de Rio de Janeiro, Brésil). Tese de Doutorado. Univ. Paris VI. $321 \mathrm{p}$.

YBERT, J.P.; SCHEEL, R.; GASPAR, M.D.

1997 Descrição de alguns instrumentos simples utilizados para a coleta e concentração de elementos fósseis de pequenas dimensões de origem arqueológica ou pedológica. Rev. MAE-USP 7: 181-189.

(*) Laboratoire de Paléoenvironnements, Anthracologie et Action de l'Homme (UPRESA 5059), Université Montpellier II. Institut de Botanique, 163 rue Auguste Broussonnet, 34090 Montpellier, França.

Recebido para publicação em 20 de setembro de 1999. 